\title{
Toward Finding a Commercial Method for Deposition of Nanostructured $\mathrm{SnO}_{2}$ Thin Films
}

\author{
N. Memarian And S.M. Rozati* \\ Physics Department, University of Guilan, 41335 Rasht, Iran \\ (Received December 17, 2011; in final form February 28, 2012)
}

\begin{abstract}
Nanostructured tin oxide $\left(\mathrm{SnO}_{2}\right)$ thin films have been prepared by spray pyrolysis technique. The effects of deposition conditions such as substrate temperature and tin chloride concentration in the precursor solution on physical properties of films have been investigated. The physical characterization of samples was carried out by UV-VIS spectroscopy, X-ray diffraction, scanning electron microscopy, and the Hall effect experiment for optical, structural, morphological and electrical studies, respectively. The films are polycrystalline in nature with a tetragonal crystal structure. The preferred orientation has been changed by changing the deposition parameters. In the case of changing the substrate temperature, (211) was found as the preferred orientation, while by changing the molarities of the solution, (301) orientation was grown as well as (211). The deposition temperature was optimized to $450^{\circ} \mathrm{C}$; whereas the optimum solution concentration was found to be $0.2 \mathrm{~mol} / \mathrm{L}$. Films deposited at foregoing conditions have good optoelectrical properties which make them suitable for applying in different optoelectronic devices.
\end{abstract}

PACS: 78.66.Fd, 73.61.-r, 73.61.Ey

\section{Introduction}

Non-stoichiometric and doped films of oxides of tin, indium, cadmium, zinc and their various alloys, deposited by numerous techniques, exhibit high transmittance in the visible spectral region, high reflectance in the IR region, and nearly metallic conductivity [1]. Tin oxide $\left(\mathrm{SnO}_{2}\right)$ films have a wide range of applications because of their excellent performance along with high mechanical, chemical and environmental stability and low cost material [1-5]. By volume, the most deposited transparent conductive oxide (TCO) today is $\mathrm{SnO}_{2}$, which is used in IR-efficient architectural window application. In addition, it is receiving more attention for photovoltaic devices (PVs), especially for the heterojunction with intrinsic thin layer (HITL) cells and related cells (such as amorphous or microcrystalline) Si [5]. Another major application of intrinsic tin oxide is using it as gas sensors $[6,7]$. Doped tin oxide, specially fluorine doped tin oxide (FTO), can be used as an ideal TCO layer in different applications such as transparent electrode in the solar cells; in one of our recent works, we applied these films for dye sensitized solar cells (DSSCs) [8].

Tin oxide films have been prepared by several methods such as chemical vapor deposition [9], spray pyrolysis [10,11], electron beam evaporation [12], sol gel [13] and sputtering [14]. Among the various deposition techniques, spray pyrolysis is well suited for the preparation of doped and undoped tin oxide thin films because of its simple and inexpensive experimental arrangement, ease

\footnotetext{
* corresponding author; e-mail: smrozati@guilan.ac.ir
}

of adding various doping materials, reproducibility, high growth rate, and mass production capability for uniform large area coatings [15].

The properties of spray deposited tin oxide thin films are dependent on the processing conditions and the nature of precursors used. The precursors play a key role in determining all the physical properties of film. $\mathrm{SnCl}_{4}$ is one of the most reported precursors for tin in the literature. Thin films of tin oxide have been prepared using $\mathrm{SnCl}_{4}$ precursor dissolved in a wide variety of solvents such as water, alcohols, or mixture of them (in various ratio) [16-18]. A series of other sources especially organic compounds with butyl groups and/or acetate groups such as TBT [19], TBTA [20], DBTDA [21] were reported to form $\mathrm{SnO}_{2}$ films. However, $\mathrm{SnCl}_{2}$ is one of the best precursors because of ease of synthesizing in the laboratory and economic considerations [22].

\section{Experimental details}

Thin films of tin oxide were deposited on glass substrates by spray pyrolysis technique. The well cleaned soda-lime glasses were used as substrates. The desired amount of stannic chloride $\left(\mathrm{SnCl}_{2} \cdot 2 \mathrm{H}_{2} \mathrm{O}\right)$, to achieve different molarities, was used as the precursor. This precursor was dissolved in $4 \mathrm{~mL}$ concentrated hydrochloric acid $(\mathrm{HCl})$ and then added with methanol served as the starting solution. Two sets of experiments have been done. Set 1: at the fixed substrate temperature $\left(450^{\circ} \mathrm{C}\right)$, different solution molarities from $0.1 \mathrm{~mol} / \mathrm{L}$ to $0.3 \mathrm{~mol} / \mathrm{L}$ were deposited; set 2 : solutions with $0.2 \mathrm{~mol} / \mathrm{L}$ concentration sprayed at substrate temperatures ranging from $400{ }^{\circ} \mathrm{C}$ to $500{ }^{\circ} \mathrm{C}$ in steps of $25^{\circ} \mathrm{C}$. The other deposition 
parameters like nozzle to substrate distance $(25 \mathrm{~cm})$, gas flow rate $(18 \mathrm{~L} / \mathrm{min}$ ) and total spray solution (40 cc) were kept constant at the optimized values indicated in parentheses.

Optical transmittance spectra of the films were measured using a UV-Vis-NIR double beam spectrophotometer by Cary100 with air as reference. The Hall effect setup supplied by Scientific Equipments, Phys. Tech. RH 2010 was used for electrical measurements by using Van der Pauw configuration at room temperature. X-ray diffraction (XRD) method was applied to determine the crystalline quality of tin oxide films by using $\mathrm{Cu} K_{\alpha}$ radiation Philips PW-1830 model. Scanning electron microscope (SEM) was carried out by Philips XL30 model for morphological analysis of the films. The thickness was calculated from the Swanepoel method by using standard formula [23]. Only for the film deposited at $500^{\circ} \mathrm{C}$, since it had no interference fringe, cross-section SEM is used for the thickness measurement.

\section{Results and discussion}

The formation of $\mathrm{SnO}_{2}$ films from a $\mathrm{SnCl}_{2}$ solution gives rise to a transitory formation of the compound $\mathrm{SnO}$. The chemical reactions taking place are [24-26]:

$$
\mathrm{SnO}+\frac{1}{2} \mathrm{O}_{2} \rightarrow \mathrm{SnO}_{2} \text {. }
$$$$
\mathrm{SnCl}_{2}+\mathrm{H}_{2} \mathrm{O} \rightarrow \mathrm{SnO}+2 \mathrm{HCl},
$$

$\mathrm{SnCl}_{2}$ can partly ionize into $\mathrm{Sn}^{2+}$ and $\mathrm{Cl}^{-}$, it could also form tin based polymer molecules [25]. On the other hand, it is reported that presence of $\mathrm{HCl}$ in $\mathrm{SnCl}_{2}$ solution forms different intermediate molecules in the starting solution. Addition of $\mathrm{HCl}$ that resulted in transparent solution may be due to the breakdown of those tin based polymer molecules. $\mathrm{SnCl}_{2} \cdot 2 \mathrm{H}_{2} \mathrm{O}$ is known to react with $\mathrm{HCl}$ to give $\mathrm{HSnCl}_{3}$. At the pyrolysis temperature, $\mathrm{HSnCl}_{3}$ is thermally decomposed to form the $\mathrm{SnO}_{2}$ molecule [24-26].

\section{Optical properties}

Figures 1 and 2 show the optical transmittance spectra obtained from the $\mathrm{SnO}_{2}$ films, in the wavelength ranging 200-900 nm, as a function of substrate temperature and molarity, respectively. The substrate temperature plays an important role in the film formation. At a temperature lower than optimum value, a powdery sample appears due to the unconverted precursor and for higher temperatures a white fog is found due to the excess amount of tin [26]. At optimum substrate temperature the spray reaches the substrate surface in the semi-vapour state and complete oxidation will take place to give clear $\mathrm{SnO}_{2}$ film. In general, in the visible region of the spectrum, the transmittance is very high. It is due to the fact that the reflectivity is low and there is no (or less) absorption due to transfer of electrons from the valence band to the conduction band owing to optical interference effects, it is possible to maximize the transmission of the thin film at particular region of wavelengths [27]. As can be seen from Fig. 2 by increasing the concentration of starting solution, the transmittance decreases. The reduction in transmission is due to increase of the thickness of deposited layer.

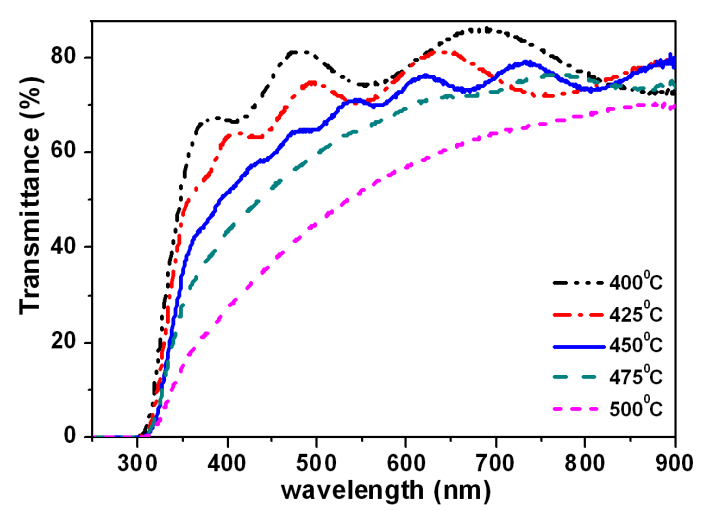

Fig. 1. Optical transmittance for spray-deposited $\mathrm{SnO}_{2}$ films deposited at various substrate temperatures.

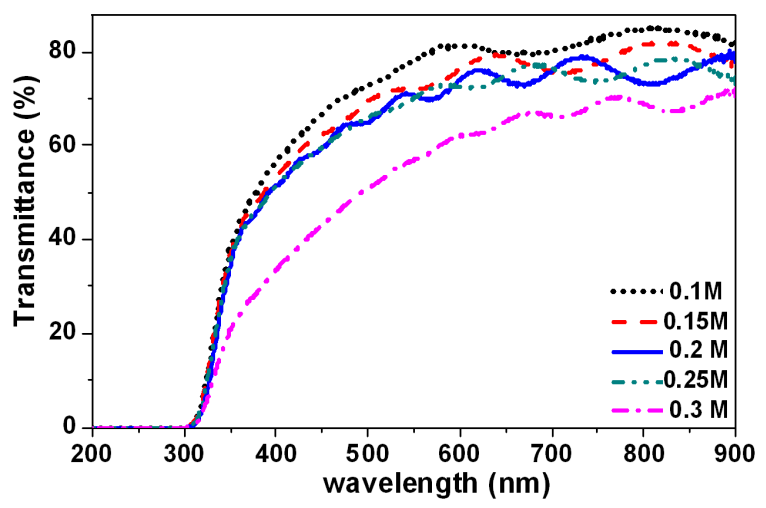

Fig. 2. Optical transmittance of $\mathrm{SnO}_{2}$ films with a function of wavelength by changing the spray solution concentration.

\section{Electrical properties}

The negative sign of the Hall coefficient, in the Hall effect experiment, confirmed the $n$-type conductivity of the samples. In Table I the electrical properties, including sheet resistance, resistivity, carrier concentration, mobility and thickness of $\mathrm{SnO}_{2}$ films are reported as a function of substrate temperature (experiments set 1) and in Table II as a function of solution concentration (set 2). The thickness of $\mathrm{SnO}_{2}$ film increases with increasing the substrate temperature and attains the maximum thickness at $450^{\circ} \mathrm{C}(1305 \mathrm{~nm})$ and then decreases for higher temperatures, which confirms that $450^{\circ} \mathrm{C}$ is the best temperature for complete decomposition of solution and pyrolysis reaction takes place in the best form. 
TABLE I

Electrical properties and figure of merit of tin oxide films deposited at different substrate temperatures.

\begin{tabular}{c|c|c|c|c|c|c}
\hline \hline$T_{\mathrm{S}}\left[{ }^{\circ} \mathrm{C}\right]$ & $t[\mathrm{~nm}]$ & $R_{\mathrm{sh}}[\Omega / \square]$ & $\rho[\Omega \mathrm{cm}]$ & $n\left[\mathrm{~cm}^{-3}\right]$ & $\mu\left[\mathrm{cm}^{2} /(\mathrm{V} \mathrm{s})\right]$ & $\Phi_{\mathrm{M}}\left[\times 10^{-3} \Omega^{-1}\right]$ \\
\hline 400 & 432 & 496 & $2.14 \times 10^{-2}$ & $7.23 \times 10^{19}$ & 4.03 & $1.0 \times 10^{-4}$ \\
425 & 611 & 309 & $1.89 \times 10^{-2}$ & $7.31 \times 10^{19}$ & 4.52 & $9.67 \times 10^{-5}$ \\
450 & 1305 & 71.8 & $9.73 \times 10^{-3}$ & $8.1 \times 10^{19}$ & 8.22 & $4.28 \times 10^{-4}$ \\
475 & 1191 & 106 & $1.26 \times 10^{-2}$ & $8.57 \times 10^{19}$ & 5.76 & $1.27 \times 10^{-4}$ \\
500 & 818 & 82.7 & $6.76 \times 10^{-3}$ & $1.66 \times 10^{20}$ & 5.57 & $1.71 \times 10^{-5}$ \\
\hline
\end{tabular}

$t$ - film thickness; $R_{\mathrm{sh}}$ - sheet resistance; $\rho$ - resistivity; $n$ - carrier concentration;

$\mu$ - carrier mobility; $\Phi_{\mathrm{M}}$ - figure of merit

TABLE II

Electrical properties and figure of merit of tin oxide films deposited at different precursor concentration.

\begin{tabular}{c|c|c|c|c|c|c}
\hline \hline Molarity $[\mathrm{mol} / \mathrm{L}]$ & $t[\mathrm{~nm}]$ & $R_{\mathrm{sh}}[\Omega / \square]$ & $\rho[\Omega \mathrm{cm}]$ & $n\left[\mathrm{~cm}^{-3}\right]$ & $\mu\left[\mathrm{cm}^{2} /(\mathrm{V} \mathrm{s})\right]$ & $\Phi_{\mathrm{M}}\left[\Omega^{-1}\right]$ \\
\hline 0.1 & 763 & 271 & $2.07 \times 10^{-2}$ & $6.70 \times 10^{19}$ & 4.50 & $3.32 \times 10^{-4}$ \\
0.15 & 917 & 120 & $1.1 \times 10^{-2}$ & $8.60 \times 10^{19}$ & 6.56 & $3.11 \times 10^{-4}$ \\
0.2 & 1305 & 71.8 & $9.37 \times 10^{-3}$ & $8.10 \times 10^{19}$ & 8.22 & $4.28 \times 10^{-4}$ \\
0.25 & 1346 & 60.4 & $8.13 \times 10^{-3}$ & $9.23 \times 10^{19}$ & 8.33 & $4.05 \times 10^{-4}$ \\
0.3 & 1791 & 21.9 & $3.92 \times 10^{-3}$ & $1.17 \times 10^{20}$ & 13.5 & $1.68 \times 10^{-4}$
\end{tabular}

The decrease in film thickness at higher substrate temperature might be due to increase in the rate of evaporation of initial ingredients.

The increase in carrier density while increasing the substrate temperature may be attributed to an enhancement in the crystallinity of the films as is indicated by the X-ray diffraction (Fig. 3) which helps to reduce the loss of carrier at the traps.

The increase in the Hall mobility, while increasing the substrate temperature, is due to an improvement in the crystalline nature of the films, which causes the reduction in resistivity of the prepared samples. Table I shows the minimum sheet resistance of $71.8 \Omega / \square$ for films deposited at substrate temperature of $450^{\circ} \mathrm{C}$. By keeping the substrate temperature constant at $450^{\circ} \mathrm{C}$ and increasing the concentration of the starting solution from $0.1 \mathrm{~mol} / \mathrm{L}$ to $0.3 \mathrm{~mol} / \mathrm{L}$, thickness of the films increased and as a result the sheet resistance and carrier mobility improved.

Using figure of merit $\left(\Phi_{\mathrm{M}}\right)$ is a good criterion to define the quality of highly transparent and conductive thin films. It is calculated by using the Haacke formula [28]:

$$
\Phi_{\mathrm{M}}=\frac{T^{10}}{R_{\mathrm{sh}}}
$$

where $T$ is the transmittance at $\lambda=550 \mathrm{~nm}$ and $R_{\mathrm{sh}}$ is the sheet resistance. Table I and Table II also show the figure of merit for the prepared films at different conditions. The highest amount of figure of merit belongs to films deposited at $T_{\mathrm{S}}=450^{\circ} \mathrm{C}$ and $0.2 \mathrm{~mol} / \mathrm{L}$ solution concentration.

\section{Structural and morphological properties}

The variations of X-ray diffraction pattern with substrate temperature are shown in Fig. 3 and with respect

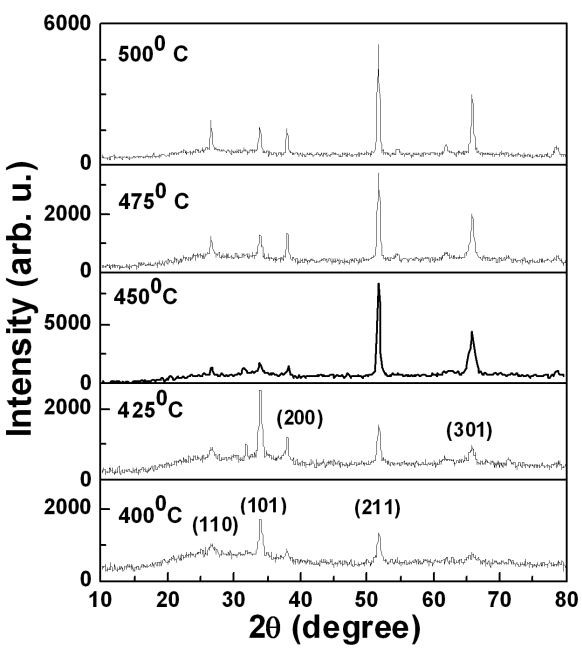

Fig. 3. XRD patterns of $\mathrm{SnO}_{2}$ thin films deposited at different conditions.

to solution molarities are shown in Fig. 4. The size of the crystallites was estimated from the XRD results using Scherrer's formula [29]:

$$
d=\frac{0.9 \lambda}{\beta \cos \theta},
$$

where $d$ is the crystallite size, $\lambda$ is the wavelength $(1.54 \AA)$ of the radiation used and $\beta$ is full width at half maximum (FWHM). When the substrate temperature is low $\left(400^{\circ} \mathrm{C}\right)$ the crystallinity is poor. There is no exact preferred orientation and the grain sizes are too small, for (101) orientation is $10 \mathrm{~nm}$ and for (211) is $14 \mathrm{~nm}$. The intensity of peaks and grain sizes increased as the substrate 
temperature increased to $425^{\circ} \mathrm{C}$, due to the improvement of the film crystallinity, at the same time other orientations such as (200) and (301) are observed. By increasing the substrate temperature to $450^{\circ} \mathrm{C}$, the crystallites undergo a reorientation. Preferred orientation has changed from (101) to (211). Furthermore, the intensity of peaks has increased and crystallite size has grown up and the crystallinity of films is improved. The grain size for (211) is about $18 \mathrm{~nm}$. After $450^{\circ} \mathrm{C}$ the intensity and crystallite size have decreased and also the intensity of the other orientations such as (110), (200) and (301) increased.

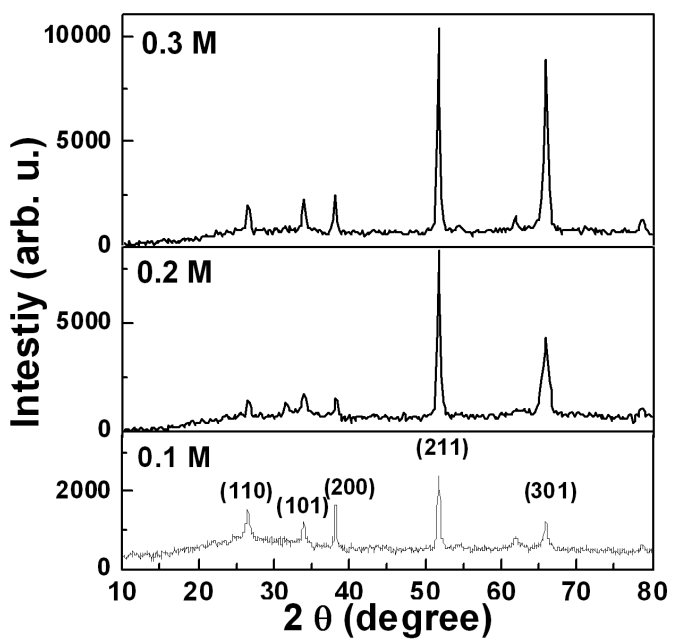

Fig. 4. XRD patterns of $\mathrm{SnO}_{2}$ thin films deposited at different conditions.

It is obvious that at a constant substrate temperature the precursor concentration controls the structure of $\mathrm{SnO}_{2}$ films. As can be seen from Fig. 4, the XRD pattern of films has changed by increasing the solution molarity. The film with $0.1 \mathrm{~mol} / \mathrm{L}$ concentration is not completely crystallized and shows diffraction peaks along (110), (101), (200), (211), and (301) planes. By increasing the molarity (in $0.2 \mathrm{~mol} / \mathrm{L}$ concentration) the intensity of (211) and (301) peaks is significantly increased (by more than 4 times) and becomes as the strongest orientation. The preferred orientation has changed to (211) whereas crystallite size is $18 \mathrm{~nm}$. In $0.3 \mathrm{~mol} / \mathrm{L}$ concentration the intensity of (301) peak increased and the crystalline sizes are $19 \mathrm{~nm}$ and $15 \mathrm{~nm}$ for (211) and (301), respectively.

Scanning electron microscope (SEM) was employed for the detailed morphological studies. Figure 5 shows a SEM micrograph of lateral fracture surface of the tin oxide film deposited at substrate temperature of $500^{\circ} \mathrm{C}$. This cross-section is used to find the thickness of the prepared film. The observed thickness was about $818 \mathrm{~nm}$.

The SEM microstructures reveal that all the films have a smooth and homogeneous surface morphology with nanocrystalline grains, also all the films are dense and without any cracks. For films with starting solution of $0.2 \mathrm{~mol} / \mathrm{L}$ concentration, deposited at different substrate

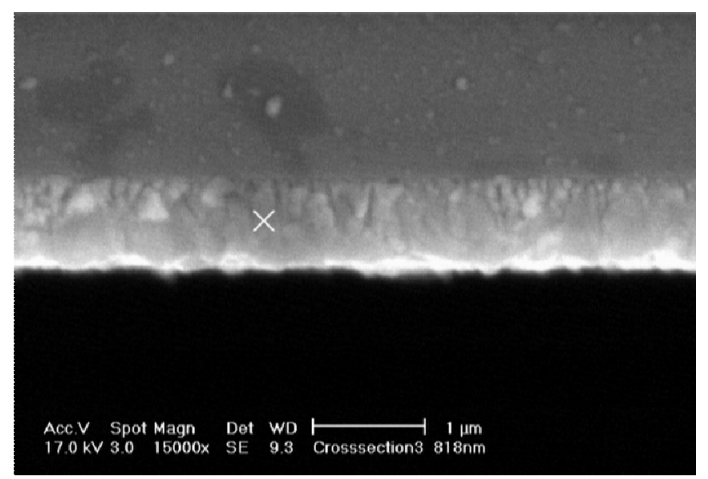

Fig. 5. Cross-section SEM image of tin oxide film prepared at $500{ }^{\circ} \mathrm{C}$.

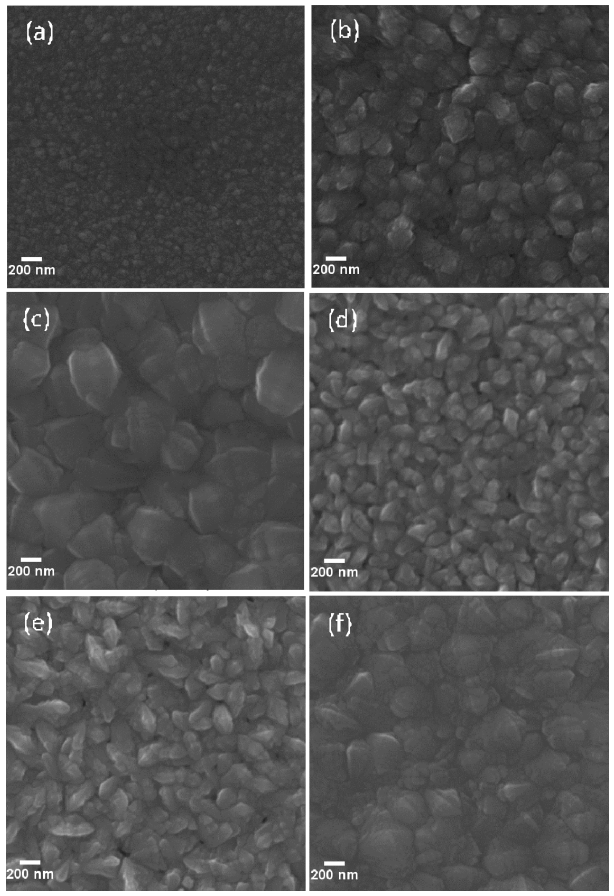

Fig. 6. SEM images of tin dioxide films deposited at different conditions: (a) $400{ }^{\circ} \mathrm{C}$, (b) $450{ }^{\circ} \mathrm{C}$, (c) $500{ }^{\circ} \mathrm{C}$, (d) $0.1 \mathrm{~mol} / \mathrm{L}$, (e) $0.15 \mathrm{~mol} / \mathrm{L}$, (f) $0.3 \mathrm{~mol} / \mathrm{L}$.

temperatures ranging from $400{ }^{\circ} \mathrm{C}$ to $500{ }^{\circ} \mathrm{C}$, the grain growth and recrystallization is observable. Figure $6 \mathrm{a}$ shows that in the SEM micrograph for film deposited at $400{ }^{\circ} \mathrm{C}$ very fine grains are distinguishable in the figure. For film deposited at $450^{\circ} \mathrm{C}$ (Fig. 6b) the grains are grown and uniformly distributed on the surface. Increasing substrate temperature to $500{ }^{\circ} \mathrm{C}$ (Fig. 6c) causes the bigger grains, which is consistent with the XRD results. Figure 6 ( $d$ to $\mathrm{f}$ ) also shows the SEM images of tin dioxide films deposited at different concentration of the starting solution from $0.1 \mathrm{~mol} / \mathrm{L}$ to $0.3 \mathrm{~mol} / \mathrm{L}$, keeping constant the substrate temperature $\left(450^{\circ} \mathrm{C}\right)$. As shown in Fig. 6 (d to $\mathrm{f}$ ), SEM microstructures indicate a uniform, granular surface morphology with small grain size. One can 
conclude from these observations that the surface roughness depends markedly on the solution molarity.

\section{Conclusions}

In this paper, transparent conductive thin films of $\mathrm{SnO}_{2}$ are grown by spray pyrolysis technique. Physical properties of deposited films namely electrical, optical, structural and morphological properties were studied. A minimum sheet resistance of $71.8 \Omega / \square$ and maximum mobility of $8.22 \mathrm{~cm}^{2} /(\mathrm{V} \mathrm{s})$ was observed for the optimum substrate temperature of $450^{\circ} \mathrm{C}$. The structural investigation revealed that the films are polycrystalline in nature with (211) as a preferred orientation. The preferred orientation and the peak intensity in XRD pattern can be changed by varying the deposition conditions. From SEM micrographs, nanocrystallites are well formed and densely packed. It was found that the highest figure of merit is obtained for the film, which is deposited at $450{ }^{\circ} \mathrm{C}$ and $0.2 \mathrm{~mol} / \mathrm{L}$ concentration and suggests its exploration for further application.

\section{References}

[1] K.L. Chopra, S. Major, D.K. Pandya, Thin Solid Films 102, 1 (1983).

[2] H. Hosono, Thin Solid Films 515, 6000 (2007).

[3] C.G. Granqvist, Thin Solid Films 515, 7025 (2007).

[4] H.L. Hartnagel, A.L. Dawar, A.K. Jain, C. Jagadish, Semiconducting Transparent Thin Films, IOP Publ. Ltd., London 1995.

[5] E. Fortunato, D. Ginly, H. Hosono, D.C. Paine, $M R S$ Bull. 32, 242 (2007).

[6] J.W. Bae, S.W. Lee, G.Y. Yeom, J. Electrochem. Soc. 154, D34 (2007).

[7] M.R. Vaezi, S.K. Sadrnezhaad, Mater. Sci. Eng. B 140, 73 (2007).

[8] N. Memarian, I. Concina, A. Braga, S.M. Rozati, A. Vomiero, G. Sberveglieri, Angew. Chem. Int. Ed. 123, 12529 (2011).

[9] S.M. Rozati, M. Maleki, in: Proc. Tth Nanoscience and Nanotechnology Conference, Istanboul, Sabanci University, Paper No. S3-I.14, Istanbul 2011.
[10] S.M. Rozati, Mater. Character. 57, 150 (2006).

[11] S.M. Rozati, F. Zarenejad, N. Memarian, Thin Solid Films 520, 1259 (2011).

[12] K.S. Shamala, L.C.S. Murthy, K. Narasimha Rao, Bull. Mater. Sci. 27, 295 (2004).

[13] E. Kuantama, D. Han, Y. Sung, J. Song, Thin Solid Films 517, 4211 (2009)

[14] M. Radecka, B. Lyson, M. Lubecka, A. Czapla, K. Zakrzewska, Acta Phys. Pol. A 117, 415 (2009).

[15] A.A. Yadav, E.U. Masumdar, A.V. Moholkar, K.Y. Rajpure, Physica B 404, 1874 (2009).

[16] A.V. Moholkar, S.M. Pawar, K.Y. Rajpure, Sol. Energy Mater. Sol. Cells 92, 1439 (2008).

[17] A.V. Moholkar, S.M. Pawar, K.Y. Rajpure, Mater. Lett. 61, 3030 (2007)

[18] S. Chacko, M. Junaid Bushiri, V.K. Vaidyan, J. Phys. D, Appl. Phys. 39, 4540 (2006).

[19] M. Okuya, S. Kaneko, K. Hiroshima, J. Eur. Ceram. Soc. 21, 2099 (2001).

[20] P.S. Patil, S.B. Sadale, S.H. Mujawar, Appl. Surf. Sci. 253, 8560 (2007).

[21] K. Murakami, K. Nakajima, S. Kaneko, Thin Solid Films 515, 8632 (2007).

[22] N. Memarian, S.M. Rozati, E. Elamurugu, E. Fortunato, Phys. Status Solidi C 7, 2277 (2010).

[23] R. Swanepoel, J. Phys. E 16, 1214 (1983).

[24] E. Elangovan, M.P. Singh, K. Ramamurthi, Mater. Sci. Eng. B 113, 143 (2004).

[25] E. Elangovan, K. Ramamurthi, Thin Solid Films $\mathbf{4 7 6}$, 231 (2005).

[26] B. Thangaraju, Thin Solid Films 402, 71 (2002).

[27] R.R. Kasar, N.G. Deshpande, Y.G. Gudage, J.C. Vyas, Physica B 403, 3724 (2008).

[28] G. Haacke, J. Appl. Phys. 47, 4086 (1976).

[29] B.D. Cullity, Elements of X-ray Diffraction, AddisonWesley Pub. Co. Inc., Boston 1978. 